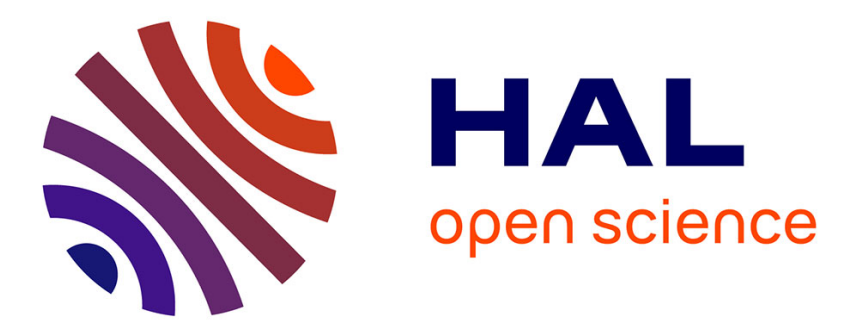

\title{
Direct determination of trace-level haloacetic acids in drinking water by two-dimensional ion chromatography with suppressed conductivity
}

Dominique Verrey, Mari-Vorgan Louyer, Olivier Thomas, Estelle Baurès

\section{- To cite this version:}

Dominique Verrey, Mari-Vorgan Louyer, Olivier Thomas, Estelle Baurès. Direct determination of trace-level haloacetic acids in drinking water by two-dimensional ion chromatography with suppressed conductivity. Microchemical Journal, 2013, 110, pp.608-613. 10.1016/j.microc.2013.07.012 . hal00877151

HAL Id: hal-00877151

https://hal-univ-rennes1.archives-ouvertes.fr/hal-00877151

Submitted on 26 Oct 2013

HAL is a multi-disciplinary open access archive for the deposit and dissemination of scientific research documents, whether they are published or not. The documents may come from teaching and research institutions in France or abroad, or from public or private research centers.
L'archive ouverte pluridisciplinaire $\mathbf{H A L}$, est destinée au dépôt et à la diffusion de documents scientifiques de niveau recherche, publiés ou non, émanant des établissements d'enseignement et de recherche français ou étrangers, des laboratoires publics ou privés. 
Direct Determination of Trace-Level Haloacetic Acids in Drinking Water by TwoDimensional Ion Chromatography with Suppressed Conductivity

\author{
DominiqueVerrey ${ }^{\mathrm{a}, \mathrm{b}, *}$, Mari-VorganLouyera,b, Olivier Thomasa,b, EstelleBaurès ${ }^{\mathrm{a}, \mathrm{b}}$ \\ aEHESP School of Public Health, Sorbonne Paris Cité, 35043 Rennes, France \\ b Inserm, U1085-IRSET, LERES,35043 Rennes, France
}

(1)

*Correspondingauthor. Tel.: +33299022948 ; fax: +33299022929.

E-mail address:Dominique.Verrey@ehesp.fr (D. Verrey).

\begin{abstract}
During thetreatment process of drinking water, disinfectants (chlorine, ozone, chlorine dioxide) react on water containing organic matter and bromide to produce disinfectionby-products at trace levels. Among them, five of the nine existing Halo-Acetic Acids (HAA) are commonly found in drinking water(Monochloroacetic acid MCAA, Dichloroacetic acid DCAA, Monobromoacetic acid MBAA,Dibromoacetic acid DBAA, and Trichloroacetic acid TCAA), including four classified in the 2B IARC group of potential carcinogens (BCAA, DBAA, DCAA, TCAA).With respect to drinking water quality, guidelines are proposed by WHO (2006) and water quality standardsare imposed in many countries such as less than $100 \mu \mathrm{g} / \mathrm{L}$ for the sum of the five HAA by US EPA (1998) and Canadian Health Department (2008).For this purpose, two analytical methods are commonly used,GC/MS with derivatization and LC/MS, UV or conductivity. A new method, based on two-dimensional ion chromatography (IC 2D) with suppressed conductivity is proposed. This method presents the main advantage compared to GC or LC methods of offering a quick implementation: direct injection, slight maintenance, lower cost of investment, by leading to good performances (specificity and sensitivity). The use of two different selectivity columns,and the fractionation on the first dimension cancelling interferences, improves the specificity. The sensitivity is enabled by interfacing a preconcentration column between the twodifferent internal diametercolumns.The analytical conditions are optimized for the analysis of nine HAA. The performances of the method are evaluated. The optimized method applied to natural water samples demonstrates its ability to quantify HAA at trace levels in drinking water.
\end{abstract}

Keywords: ionic chromatography; two dimensions; capillary; haloacetic acids; drinking water

\title{
1. Introduction
}

\subsection{Formation, occurrence and regulation of disinfection by-products}

During thedisinfection step of drinking water treatment process, disinfectants (chlorine, ozone, chlorine dioxide) react on water containing organic matter and bromide to produce disinfection by-products(DBPs). Among the six hundred substances identified, haloacetic acids (HAAs) and trihalomethanes (THM) represent the two major classes and thirty percent on a weight basis $[1,2]$.

Among the HAAs, nine bromo and/or chloroacetic acids combinations are possible:monochloroacetic acid (MCAA), dichloroacetic acid (DCAA), trichloroacetic acid (TCAA), 
monobromoacetic acid (MBAA), dibromoacetic acid (DBAA),bromochloroacetic acid (BCAA), bromodichloroacetic acid (BDCAA), dibromochloroacetic acid (DBCAA), tribromoacetic acid (TBAA).

Five of these nine HAA (MCAA, DCAA, TCAA, MBAA, DBAA) were commonly found in drinking water in the US, with a mean concentration of $23 \mu \mathrm{g} / \mathrm{L}$ [3]. In other countries, DCAA and TCAA between $2 \mu \mathrm{g} / \mathrm{L}$ and $12 \mu \mathrm{g} / \mathrm{L}$ were analysed in Canada [4],DCAA (from $0.4 \mu \mathrm{g} / \mathrm{L}$ to $13 \mu \mathrm{g} / \mathrm{L}$ )and TCAA (from $0.6 \mu \mathrm{g} / \mathrm{L}$ to $11 \mu \mathrm{g} / \mathrm{L}$ ) in drinking water in China [5], up to $49.5 \mu \mathrm{g} / \mathrm{L}$ for the sum of the five HAA in tap water in Seoul [6], from 0.9 to $87 \mu \mathrm{g} / \mathrm{L}$ for the sum of the nine inSpain[7]. Regarding the seasonal influence, the five HAA concentrations were 1.0-38.9 $\mathrm{\mu g} / \mathrm{L}$ in winter and $0.2-46.7 \mu \mathrm{g} / \mathrm{L}$ in summer, in drinking water of Taiwan, DCAA and TCAA being the two major HAA (around 30\% and 26\% respectively) [8].

In the International Agency for Research on Cancerclassification [9], four of the nine HAA are classified in the 2B group aspossibly carcinogenic to humans (BCAA [10], DBAA [11], DCAA [12], TCAA $[13,14]$ ). World Health Organization (WHO)proposes guidelines for drinking water as a point of departure for national authorities to determine drinkingwaterregulations and standards [15]. WHO has established guidelines for chlorinated HAA(MCAA: $20 \mu \mathrm{g} / \mathrm{L}$; DCAA: $50 \mu \mathrm{g} / \mathrm{L}$; TCAA: $200 \mu \mathrm{g} / \mathrm{L}$ ), but not for brominated HAA. The national authoritiesapproaches are different according to countries. For example,on the sum of the five commonly found HAA, the US EPAhas fixed regulation at $60 \mu \mathrm{g} / \mathrm{L}$ in 1998 [16] andHealth Canadahas fixed recommandation at $80 \mu \mathrm{g} / \mathrm{L}$ in 2008 [17]. In Europe, HAA are not yet standardizeddespitean increasing demand of sanitary surveysas for example, campaigns in four drinking water systems in France [18].

\subsection{State of the art of analytical methods}

HAA analysis is usually performed by GCorLC techniques (Table 1). The GCmethods require two steps of sample preparation, a liquid-liquid extraction (LLE) and anextract concentration $[19,20]$. To reduce the extraction volume during sample preparation, new techniques have been developed such as the liquid-liquid microextraction [21] andthe single-drop microextraction (SDME) [22].A recent procedure combining liquid-liquid microextraction and headspace (HS)GCmay allow reducing the time of sample preparation [23]. In order toget volatile compounds, a derivatization step is carried out before injection of the extract into the gas chromatograph. Two types of detectors are available:(i) the electron capture detector (ECD), specific for halogenated substances, has a good sensitivity but requires training and protection precautions against the radioactive source and (ii)the mass spectrometer (MS) provides better security identification. The main advantage of GC methods is a goodsensitivity with limits of detection (LOD) between 0.01 and $1.2 \mu \mathrm{g} / \mathrm{L}$ according to the method and the substance, as shown in Table 1. Howeverthe sample preparation steps areheavy to run and time-consuming, which may considerGCanalysis of HAAtedious and expansive[19,20].

LC methods aredivided into two categories: (i) reversed-phaseliquid chromatography [24] and (ii) ion chromatography (IC)[25]. Regardless on the technique used, the sample is either injected directly or after a preconcentration step(online or offline) on a solid phase extraction (SPE) cartridge.Direct LC methods can be achieved thanks to anelectromembrane extraction (EME) followed byUV detection[26] or a LC/MS/MS technique[27]. Several types of detectionare available with IC methods, the most frequent being conductimetry(CD) [25], possibly with preconcentration SPE cartridge for a better sensitivity [28]. The second type of IC detection is MS, often used in tandem $[29,30]$. A third type of IC detectionis fluorimetry(FL), associated with 
post-column reaction (PCR) [31]. All LC techniques avoid the tedious steps of sample treatment for GC, with LODbetween $0.0007 \mu \mathrm{g} / \mathrm{L}$ and $35.4 \mu \mathrm{g} / \mathrm{L}$ as shown in Table 1 . The wider range of LOD with regard to GC is explained by the different techniques proposedfor separation and detection.With GC or LC, MS detectionrequiresmore staff qualificationand higher costs of investment and maintenance than the use of specific detectors, but has the advantages of more reliability and specificity.Overall the performances of all methods presented are in compliance with recommendations and regulations for water quality.

\section{Please insert Table 1 here}

\subsection{Principle of the two-dimensional ion chromatography (IC 2D)}

The method proposed hereafterallows to separate the nine HAA usinga two-dimensional ion chromatography separation with a conductimetric detection (IC 2D). The interest of the method is the improvement of the sensitivity (thanks to two different diameters ofsuccessive columns) and the specificity (different phases). Acollection window enablesthe selection of anions of interest on a column concentrator during the first step (first dimension). Thus, these anions are eluted during the second step (second dimension). The two successive separations on two columns of different diameters (an analytical column and a capillary column) with a concentration step between the two columns, increase the sensitivity by the square of the ratio of the two columns diameters.

\section{Material and methods}

\subsection{Chemicals}

All chemicals used to prepareHAA standards solutions were of analytical grade purity and were obtained from Merck (Darmstadt, Germany). Individual haloacetic acids DCAA, BDCAA and BCAA were obtained from Supelco(Bellefonte, PA, USA), MCAA and TCAA from Fluka (Saint-Louis, MO, USA), MBAA, DBAA and TBAA from DrEhrenstorfer(Augsburg, Germany) and BCAA from Aldrich(Chicago, IL, USA).

Stock solutions of individual HAA were prepared in ultra-pure water (UPW) at a concentration of $1 \mathrm{~g} /$ Land stored in the dark at $5+/-3^{\circ} \mathrm{C}$. Working standards were daily fresh preparedat the concentrations range.

Stocks solutions of 10 inorganics anions (fluoride, chlorite, bromate, chloride, nitrite, bromide, chlorate, nitrate, sulfate, orthophosphate), at $1 \mathrm{~g} / \mathrm{L}$,used for interferences study were obtained from Merck (Darmstadt, Germany) and Carlo Erba (Val de Reuil, France).

UPWwasobtained by a Millipore (Bedford, MA, USA) Rios30 system coupled with a Milli Q Gradient water purification system.

\subsection{Instrumentation}

For this study, aThermo Scientific DionexICS 5000 ion chromatograph (Sunnyvale, CA, USA) was employed. It is composed from several modules: AS-AP Autosampler, Dual Pump (DP) module, Eluent Generator (EG) module and Dectector/Chromatography(DC) module. Instrument control, 
acquisition and data processing were performed usingChromeleon 6 software. The ICS 5000 is configured with two complete chromatographic systems in tandem as shown in Figure 1.

\section{Please insert Figure 1 here}

The two systems have a few but important differences. Each of both has: i) a gradient pump (P1, P2) for potassium hydroxide (KOH)eluent introduction,produced by an on line automatic eluent generation system (EGC KOH); ii) a continuous regenerating-anion trap column (CR-ATC) for eluent carbonates removal; iii) a chromatographic column (C1, C2) ; iv) an electrolytic suppressor (S1, S2);v) a carbonate removal device trapping sample carbonates (CRD300, CRD200); vi) a conductivity detector (CD1, CD2);vii) a waste (W).

The differences are i) the flow rates of the gradient pumps $(1 \mathrm{~mL} / \mathrm{min}$ for $\mathrm{P} 1$ and $0.012 \mathrm{~mL} / \mathrm{min}$ for P2); ii) the characteristics and nature of columns (C1:analytical guard column AG24 [50 44 $\mathrm{mm}]+$ analytical column AS24 $[250 \times 4 \mathrm{~mm}]$ at $10^{\circ} \mathrm{C}$; C2: capillary guard column AG26 [50 0.4 $\mathrm{mm}]+$ capillary column AS26 $[250 \times 0.4 \mathrm{~mm}]$ at $\left.15^{\circ} \mathrm{C}\right)$; iii) the characteristics of electrolytic suppressors (S1: Anion Self Regenerating Suppressor (ASRS) 300 in external regeneration modewith NaOH 10 mM;S2: Anion Capillary Electrolytic Suppressor(ACES)in recycle regeneration mode); iv) the characteristics of carbonate removal device (CRD 300: external regeneration mode; CRD 200:self-regeneration capillary device).

The first system has an injection valve for sample introduction (V). $500 \mu \mathrm{L}$ of samples are injected thanks to the AS-AP autosamplerregulated at $10^{\circ} \mathrm{C}$. In order to limit sample volume, the sampler is used in partial loop mode with a $750 \mu \mathrm{L}$ volume loop.

After the separation on the System 1, fractions of interestare automatically collected thanks to a Rheodyne valve (Rohnert Park, CA, USA) and reinjected onto a Thermo Scientific Dionex Monolith Anion Concentrator column 200 IonSwift MAC-200(capacity $0.24 \mu \mathrm{eq}$ ) before injection in the System 2.

\subsection{Method}

\subsubsection{Optimization method}

After the identification of each retention time of the 9 HAAs and the 10 common inorganic anions, in both dimensions, the method optimization wasperformed in order to separate or eliminate the interferences fromthe interest compounds. The different steps of this optimization are related to (i)the sample preparation, (ii) the eluent concentration and its gradient,(iii)the temperature of the columns, and (iv) thefirst dimension collection windows.

\section{Samples preparation}

According to standard ISO 23631 [19], the addition of sodium thiosulfate at10 mg/L allowedto stop residual chlorine action and to eliminate the interference of the chlorite on MBAA.

\section{Eluent concentration and gradient}

First chromatographicseparation was carried out with the eluentgradient: $3 \mathrm{mM}$ (hold $15 \mathrm{~min}$ ), first ramp at $0.46 \mathrm{mM} / \mathrm{min}$ to $15 \mathrm{mM}$, second ramp at $500 \mathrm{mM} / \mathrm{min}$ to $65 \mathrm{mM}$ (hold19 $\mathrm{min}$ ) and third ramp at $7.75 \mathrm{mM} / \mathrm{min}$ to $3 \mathrm{mM}$ (hold $3 \mathrm{~min}$ to reach an analysis time of $72 \mathrm{~min}$ ).

Second chromatographic separation was carried out with the eluent gradient: $6 \mathrm{mM}$ (hold 50 $\mathrm{min}$ ), first ramp at $500 \mathrm{mM} / \mathrm{min}$ to $160 \mathrm{mM}$ (hold $7 \mathrm{~min}$ ), second ramp at $500 \mathrm{mM} /$ minto 130 
$\mathrm{mM}$ and immediately third ramp at $9.54 \mathrm{mM} / \mathrm{min}$ to $6 \mathrm{mM}$ (equilibration time of $2 \mathrm{~min}$ to reach an analysis time of $72 \mathrm{~min}$ ).

\section{Temperature}

According to Barron et al. [32], the temperature changes have kinetic and thermodynamic effects in IC. In this studyseveral temperatures from 10 to $30^{\circ} \mathrm{C}$ were tested.

\section{Collection windows}

Three collection windows were determined for respectively mono, di and tri HAAsbased on their retention times. This fractionation enabled collecting compound of interest on the preconcentration column.

\subsubsection{Quantitation method}

According to NF EN ISO 10304-1 [33], the resolution factor $\mathrm{R}_{1,2}$ between two substances is defined as $R_{2,1}=2\left(t_{R 2}-t_{R 1}\right) /\left(w_{2}-w_{1}\right)$ (with: $R_{2,1}$ Resolution factor between species 1 and $2, t_{R}$ retention time in seconds, w peak width in seconds).Limits of quantification (LOQs) were defined as the lowest concentrationfor which the relative standard deviation (RSD)of replicateinjections is lower than or equal to $20 \%$ and the signal-to-noise ratio (S/N)greater than 10. LOQs were estimated by analyzing UPW spiked with decreasing amounts of analytes. Quadratic calibration curves wereestablished for each HAA by spiking UPW with five different amounts of HAAs (from theestimated LOQ to $200 \mu \mathrm{g} / \mathrm{L}$ depending on the compound).The determination coefficient was calculated in a quadratic mode. It reflects the deviation of the measured data points from the calibration curve.The LOQ bias was calculated as the difference between the theoretical LOQ and the measured LOQ divided by the theoretical LOQ.Therecovery was calculated as the value experimentally obtained from calibration graph divided by the theoretical value.The limit of detection (LOD) was determined as the LOQ divided by 3.The results of the reference GC method and the IC method were tested using the Student t test for paired samples to determine if they were statistically the same or different.

\section{Results and discussion}

\subsection{Chromatographic separation}

To optimize the separation of the 9 HAA from each other and from the 10 mineral interferentanions on the two dimensions, the elution gradient was optimized, from 3 and $6 \mathrm{mM}$ of potassium hydroxide to separate the mono and dihaloacetic acids from each other, up to 60 mMand more for the4trihaloacetic acids.

On the first dimension, two factors were taken into account forthe optimization of separation. Firstly, the collection windows, defined as the intervals of retention times within which are separated compounds of interest, were adjusted to enable HAAs to go to the preconcentration cartridge while eliminating interfering mineral anions when possible. The intervals of windows were determined for the monohaloacetic acids, dihaloacetic acids and trihaloacetic acids between 20.0 and $27.1 \mathrm{~min}$., 33.5 and $39.8 \mathrm{~min} ., 47.9$ and $58.0 \mathrm{~min}$. respectively. 
Secondly, the variation ofcolumn temperature from $15^{\circ} \mathrm{C}$ to $10^{\circ} \mathrm{C}$ had an impact on the separation ofthe two coelution cases concerning bromate/MBAA and nitrite/DBAA. For example, resolutions between bromate and MBAA at $15.0^{\circ} \mathrm{C}, 12.5^{\circ} \mathrm{C}$ and $10.0^{\circ} \mathrm{C}$ were determined at 1.1, 1.4 and 1.7 respectively.The better separation was observed on the coelutionof bromate/MBAA with $10^{\circ} \mathrm{C}$, according to the resolution criterion that the separation between two substances must be greater or equal to 1.3 .

On the second dimension, a coelution was observed forchlorite and MCAA. An addition of sodium thiosulfate, reacting on chlorite ion, led to its elimination. The chromatogram in Figure 2 shows the optimized separation on this dimension.

\section{Please insert Figure 2here}

\subsection{Instrumental performances}

For the nine substances, the calibration was made with quadratic model, using a second order equation $(\mathrm{F}(\mathrm{x})=\mathrm{C} 0+\mathrm{C} 1 \times \mathrm{x}+\mathrm{C} 2 \times \mathrm{x} 2)$. The calibration range was validated from the LOQ to 100 $\mu \mathrm{g} / \mathrm{L}$, with determination coefficients higher than 0.999 as presented in Table 2 .

\section{Please insert Table 2 here}

The secondstep of performances validation (Table 3) was the determination of the limit of quantification (LOQ). The mixtures of the nine HAA in UPW, analyzed at known concentrations were quantified according to calibration functions.LOQ were equal [30] or higher than the ones obtained by other methods such as GC $[18,19,21,22]$ or IC/MS $[28,29]$, and even lower than classical IC [24,27].

Spikes of HAA ( $20 \mu \mathrm{g} / \mathrm{L})$ in real samples, especially drinking water, enabled to verify the possible matrix impact. The recovery rates presented in Table 3were between 88 and 119\%, excepted forTCAA (60\%), probably because of a problem of optimization(beginning of the substance elution out of the collection window).

\section{Please insert Table 3here}

\subsection{Application to natural water in treatment process and comparison with GC analysis}

One river was sampled four different days and was treated in a drinking water treatment pilot. At the step of disinfection, $4 \mathrm{mg} / \mathrm{L}$ chlorine were added during several contact-times $(3 \mathrm{~h}, 24 \mathrm{~h}$, 72h). HAA were analyzed with IC 2D on the twelve chlorinated samples. An available method measuring MCAA, DCAA, TCAA and DBAA with LLE/Derivatization/GC/MS was applied to the samples [34].

The analytical results obtained from the two methods are presented in Table 4 . The $t$ test was used to read the results.For MCAA, TCAA and DBAA, the $t$ test value was inferior to the $t$ test T5\% value. It means that the averages of the two methods are not significantly different. For $\mathrm{TCAA}$, the $\mathrm{t}$ test value was superior to the $\mathrm{t}$ test $\mathrm{T} 5 \%$ value. It means that the averages of the two methods are significantly different, with a difference of $2.1 \mu \mathrm{g} / \mathrm{L}$. Moreover given the fact that trace levels near LOQ are measured, the results werejudged acceptable.

\section{Please insert Table 4here}




\section{Conclusion}

The method based on IC 2D developed for 9 HAA shows interestingperformances in terms of limits of quantification, linearity and accuracy, regarding the need for drinking water quality control for sanitary survey. The practical advantages of the method are demonstrated: fast sample preparation, sensitivity around one microgram per liter and comparable results with a GC method. Starting from these first results, the perspective is, on one hand, to expand this method to other matrices while verifying the absence of specific interferences and, on the other hand, to refine the performance evaluation foreach matrix according to analytical standard (e.g.NF T 90-210).

\section{Acknowledgements}

We thank Anne-Marie Compiano(ThermoFisher) for her advises, and Ianis Delpla for the chlorinated river samplespreparation.

\section{References}

[1] B. Chen, P.Westerhoff, Predicting disinfection by-product formation potentialin water, Water Res. 44 (2010) 3755-3762.

[2] S.W. Krasner, H.S. Weinberg, S.D. Richardson, S.J. Pastor, R. Chinn, M.J. Sclimenti, G.D. Onstad, A. D. Thruston, Occurrence of a new generation of disinfection byproducts,Environ. Sci. Technol. 40 (2006) 7175-7185.

[3] S.D. Richardson, M.J. Plewa, E.D. Wagner, R.Schoeny, D.M. DeMarini, Occurrence genotoxicity and carcinogenicity of regulated andemerging disinfection by-products in drinking water: a review and roadmap for research, Mutat. Res. 636 (2007) 178-242.

[4] M.J. Rodriguez, J. Serodes, D. Roy, Formation and fate of haloacetic acids (HAAs)within the water treatment plant, Water Res. 41 (2007) 4222-4232.

[5] H. Zhou, X.J. Zhang, Z.S. Wang, Occurrence of haloacetic acids in drinking water in certain cities of China, Biomed. Environ. Sci., 17(2004)299-308.

[6] J. Lee, E.S. Kim, B.S.Roh, S.W.Eom, K.D.Zoh, Environ.Monit.Assess., DOI10.1007/s10661-0133127-1, Accepted February 2013

[7] C.M.Villanueva, G. Castano-Vinyals, V. Moreno,G. Carrasco-Turigas, N. Aragones, E. Boldo, E. Ardanaz, E. Toledo,J.M.Altzibar, I. Zaldua, L. Azpiroz, F. Goni, A. Tardon, A.J. Molina,V. Martin, C. Lopez-Rojo, J.J. Jimenez-Moleon, R.Capelo,I. Gomez-Acebo, R. Peiro, M. Ripoll, E. GraciaLavedan,M.J. Nieuwenhujsen, P. Rantakokko, E.H.Goslan, M. Pollan, M. Kogevinas, Environ.Res.114(2012)1-11.

[8] H. H. Chang, H. H. Tung, C. C. Chao, G. S. Wang, Occurrence of haloacetic acids (HAAs) and trihalomethanes (THMs) in drinking water of Taiwan, Environ.Monit.Assess., 162 (2010) 237250.

[9] IARC, Preamble in: IARC, Monographs on the Evaluation ofCarcinogenic Risks to Humans, Lyon, 2006. 
[10]IARC, Bromochloroacetic acid in: IARC, Some Chemicals Present in Industrial and Consumer Products, Food and Drinking-water, IARC Monographson theEvaluation of Carcinogenic Risks to Humans, Lyon, 101, 2011, pp. 495-511.

[11]IARC, Dibromoacetic acid in: IARC, Some Chemicals Present in Industrial and Consumer Products, Food and Drinking-water, IARC Monographs on the Evaluation of Carcinogenic Risks to Humans, Lyon, 101, 2011, pp. 513-531.

[12]IARC, Dichloroacetic acid in: IARC, Some Drinking-water Disinfectants and Contaminants, including Arsenic, IARC Monographs on the Evaluation of Carcinogenic Risks to Humans, Lyon, 84, 2004, pp. 359-402.

[13]IARC, Trichloroacetic acid in: IARC, Some Drinking-water Disinfectants and Contaminants, including Arsenic, IARC Monographs on the Evaluation of Carcinogenic Risks to Humans, Lyon, 84, 2004, pp. 403-440.

[14]IARC, List of classifications by alphabetical order in: Agents Classified by the IARC Monographs, Lyon, 2013, pp. 1-33.

[15] WHO, Guidelines for Drinking Water Quality,fourth ed., Geneva, 2011.

[16] USEPA, National Primary Drinking Water Regulations:Disinfectants andDisinfection ByproductsFinal Rule,Federal Register, Washington,63, 1998, pp. 69396.

[17] Santé Canada, Guidelines for Canadian Drinking Water Quality:Guideline Technical Document, Haloacetic Acids, Ottawa, 2008, pp. 71.

[18] INVS, AFSSA, Damien Mouly, Eric Joulin, Christophe Rosin, Pascal Beaudeau, Abdelkrim Zeghnoun,Agnès Olszewski-Ortar, Jean-François Munoz, Les sous-produits de chlorationdans l'eau destinéeà la consommation humaineen France, Saint-Maurice, 2009.

[19] ISO, Water quality, Determination of dalapon, trichloroacetic acid and selected haloacetic acids, Method using gas chromatography (GC-ECD and/or GC-MS detection) after liquid-liquid extraction and derivatization, ISO 23631, Geneva, 2006.

[20] A. Nikolaou, S. Golfinopoulos, L. Rizzo, G. Lofrano, T. Lekkas, V. Belgiomo, Optimization of analytical methods for the determination ofDBPs: Application to drinking waters from Greece and Italy, Desalination, 176 (2005) 25-36.

[21] US EPA, Determination of haloacetic acids and dalapon in drinking water by liquid-liquid microextraction, derivatization, and gas chromatography with electron capture detection, Washington, 552.3, 2003.

[22] M.Saraji, A.A.H.Bidgoli,Single-drop microextraction with in-microvialderivatization for thedetermination of haloacetic acids in water sample by gaschromatography-mass spectrometry, J.Chromatogr. A, 1216 (2009) 1059-1066.

[23] M.J. Cardador, A. Serrano, M. Gallego, Simultaneous liquid-liquid microextraction/methylation for the determinationof haloacetic acids in drinking waters by headspace gas chromatography, J.Chromatogr. A, 1209 (2008) 61-69.

[24] Y.Li, J.S. Whitaker, C.L. McCarty, Analysis of iodinated haloacetic acids in drinking water by reversed-phase liquidchromatography/electrospray ionization/tandem mass spectrometry with largevolume direct aqueous injection,J.Chromatogr.A, 1245 (2012) 75- 82. 
[25] H.T. Fu, L.M. Zhao, M. Luo, H.Y. Zhang, J. Zhang, Determination of chloraceticacids in drinking water by ion chromatography using silver oxide as precipitant eliminating interference of chlorate in matrix, Chin. J. Anal.Chem., 36 (2008), 1407-1410.

[26] K.Alhooshania, C.Basheera, J.Kaurb, A.Gjelstadc, K.E. Rasmussenc, S. Pedersen-Bjergaardc, H.K.Leeb, Electromembrane extraction and HPLC analysis of haloacetic acids and aromaticacetic acids in wastewater,Talanta, 86 (2011) 109- 113.

[27] L.Meng, S. Wu, F. Ma, A.Jia, J. Hu, Trace determination of nine haloacetic acids in drinking water by liquidchromatography-electrospray tandem mass spectrometry, J.Chromatogr. A, 1217 (2010) 4873-4876.

[28]M.C.Bruzzoniti, R.M. De Carlo, K. Horvath, D.Perrachon,A. Prelle, R.Tofalvi, C.Sarzanini, P.Hajos,High performance ion chromatography of haloaceticacids on macrocycliccryptand anion exchanger, J.Chromatogr. A, 1187 (2008) 188-196.

[29] M.C. Prieto-Blancoa, M.F. Alpenduradab, P. Lopez-Mahiaa, S. Muniategui-Lorenzoa, D. PradaRodrigueza, S. Machadob, C. Goncalves, Improving methodological aspects of the analysis of five regulated haloaceticacids in water samples by solid-phase extraction, ion-pair liquidchromatography and electrospray tandem mass spectrometry, Talanta 94 (2012) 90- 98.

[30] US EPA, Determination of haloacetic acids, bromate, and dalapon in drinking water by ion chromatography electrospray ionization, tandem mass spectrometry (IC-ESI-MS/MS), Washington, 557, 2009.

[31] P.S. Simone, P.L. Ranaivo, G.Geme, M.A. Brown, G.L. Emmert, On-line monitoring of nine haloacetic acid species at the $\mu \mathrm{gL}-1$ level usingpost-column reaction-ion chromatography with nicotinamide fluorescence, Anal.Chim.Acta, 654 (2009) 133-140.

[32] L. Barron, P.N. Nesterenko, B. Paull, Use of temperature programming to improve resolutionof inorganic anions, haloacetic acids and oxyhalides in drinking water by suppressed ion chromatography, J.Chromatogr. A, 1072 (2005) 207-215.

[33] AFNOR, Determination of dissolved anions by liquid chromatography of ions, Determination of bromide, chloride, fluoride, nitrate, nitrite, phosphate and sulfate, La Plaine Saint-Denis,10304-1, 2009.

[34] Université de Rennes 1, I. Delpla, Facteurs climatiques etdégradation de la qualitéphysicochimique deseaux de surface destinéesà la consommationhumaine en zone agricole, Rennes, 2011.

\section{Captions}

Table 1: Existing methods for HAA analysis

Figure1.Schematic diagram of the two-dimensional chromatographic system (see explanations in text)

Figure 2. Second dimension chromatogram with a mix of $9 \mathrm{HAA}$ at $20 \mu \mathrm{g} / \mathrm{L}$ each

Table 2: Calibration characteristics

Table 3: Performances in water 
367 Table 4: Comparison between GC and IC 2D methods 